\title{
Synthesis of pyrazole, 1,3-dithiolan and thiophene derivatives pendant to thiazolo[2,3-c]-1,2,4-triazole moiety
}

\author{
Samia Mohamed Sayed, Mohamed Ali Khalil and Mohamed Abd-Elmonem Raslan* \\ Chemistry Department, Faculty of Science, Aswan University, 81528 Aswan, Egypt \\ *Corresponding author at: Chemistry Department, Faculty of Science, Aswan University, 81528 Aswan, Egypt. \\ Tel.: +2.097.2319197. Fax: +2.097.3480450. E-mail address: raslanma47@yahoo.com (M.A. Raslan).
}

\section{ARTICLE INFORMATION}

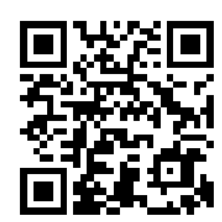

DOI: 10.5155 /eurjchem.5.2.356-362.1022

Received: 25 January 2014

Received in revised form: 27 February 2014

Accepted: 04 March 2014

Online: 30 June 2014

\section{KEYWORDS}

\section{Thiophene}

1,3-Thiazole

1,3-Dithiolane

S,S-Dithioacetal

3-Oxopropanenitrile

Thiazolo[2,3-c]-1,2,4-triazole

\section{Introduction}

Heterocycles are widely used in the development of modern pharmaceuticals; this is being one of the reasons why continuous efforts are placed towards the design of amenable synthetic approaches for the synthesis of new heterocyclic systems. Thiazole ring systems are known to possess various pharmacological properties such as anti-tubercular, antifungal, analgesic and anticancer activities [1-4].

1,2,4-Triazole and their derivatives are found to be associated with various biological activities such as anticonvulsant [5-7], antifungal [8-10], anticancer [11-14], antiinflammatory [15-17] and antibacterial properties [18-21]. In addition, compounds incorporating 1,2,4-triazole and 1,3thiazole have been attracting widespread attention due to their diverse pharmacological such as antimicrobial, antiinflammatory and antitumor activities [22,23].

Also, pyrazoles have emerged as a group of compounds possessing a broad spectrum of useful medicinal such as herbicide, fungicide and analgesic activities [24-26]. On the other hand many thiophene containing compounds including annulated compounds, exhibit biological activities [27-29].

Based on the above observations, we expected that incorporation of the above various nuclei will yield compounds with enhanced biological activities and as a part of our research program aimed at developing simple and efficient synthetic approaches for fused ring systems with bridgehead nitrogen atom, utilizing the inexpensive and readily obtainable starting materials like 5-acety-2-amino-4-methylthaizole [30-35], we report here on the utility of the highly versatile, multifunctional intermediates $\mathbf{6}$ and $\mathbf{7}$ as building blocks for the synthesis of the title compounds.

\section{Experimental}

\subsection{Instrumentation}

Melting points were determined on a Gallenkamp apparatus and are uncorrected. The IR spectra were recorded on Shimadzu FT-IR 8101 PC infrared spectrophotometer. The ${ }^{1} \mathrm{H}$ and ${ }^{13} \mathrm{C}$ NMR spectra were determined in DMSO- $d_{6}$ at 300 and $75 \mathrm{MHz}$, respectively, on a Varian Mercury VX $300 \mathrm{NMR}$ spectrometer using TMS as an internal standard. Mass spectra were measured on a GCMS-QP1000 EX spectrometer at $70 \mathrm{eV}$. Elemental analyses were carried out at the Microanalytical Center of Cairo University.

\subsection{Synthesis}

2.2.1. Synthesis of N'-(5-acetyl-4-methylthiazol-2-yl)-2-oxo propanehydrazonoyl chloride (3) 


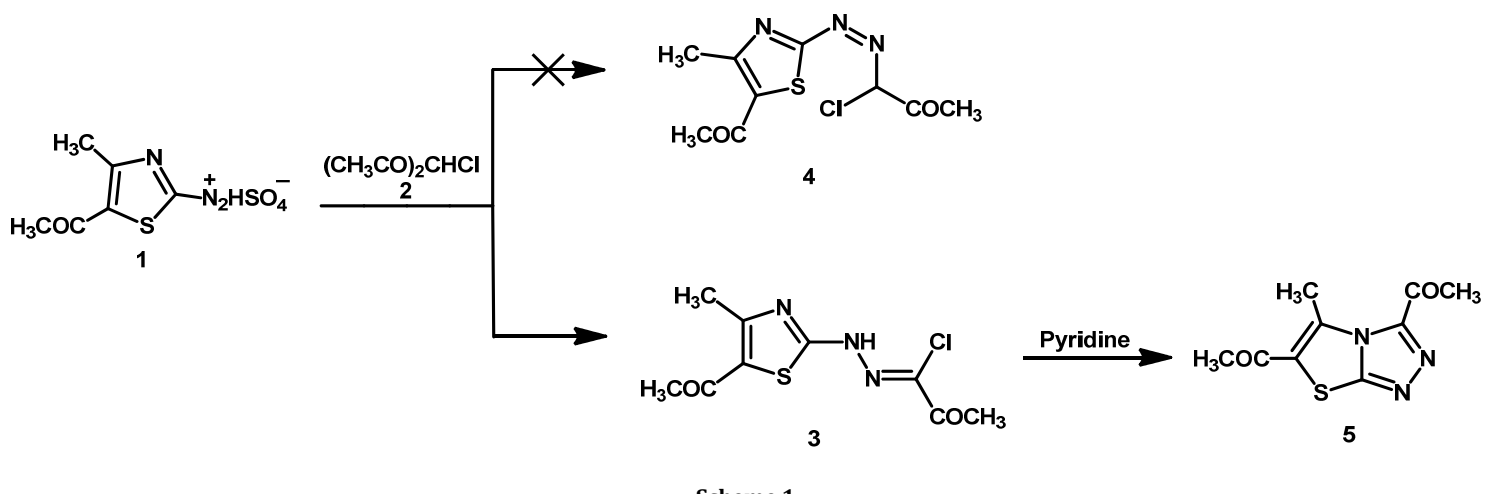

Scheme 1

5-Acetyl-2-amino-4-methylthiazole salt (1) was prepared according to the reported literature [36]. The freshly diazonium salt $1(10 \mathrm{mmol})$ was added portionwise with stirring to a cold solution $\left(0-5{ }^{\circ} \mathrm{C}\right)$ of 3-chloropentane-2,4-dione (2) $(10 \mathrm{mmol})$ in ethanol $(50 \mathrm{~mL})$ in the presence of AcONa. $3 \mathrm{H}_{2} \mathrm{O}(2 \mathrm{~g})$ over period of $30 \mathrm{~min}$. The reaction mixture was stirred for further $2 \mathrm{~h}$, at $0-10{ }^{\circ} \mathrm{C}$ then kept in an ice box for $24 \mathrm{~h}$. The precipitate product was filtered off, washed with water, dried and finally recrystallized from dioxane to afford of the hydrazone 3 (Scheme 1). Yield: 55\%. M.p.: $205-207^{\circ}$ C. FTIR (KBr, v, cm-1): 3340, $3150(\mathrm{NH}), 1693,1686$ (2C=0). ${ }^{1} \mathrm{H}$ NMR (300 MHz, DMSO- $d_{6}, \delta, \mathrm{ppm}$ ): $2.32\left(\mathrm{~s}, 3 \mathrm{H}, \mathrm{CH}_{3}\right), 2.63$ (s, $3 \mathrm{H}$, $\left.\mathrm{CH}_{3}\right), 2.74$ (s, 3H, $\left.\mathrm{CH}_{3}\right), 9.88$ (s, $1 \mathrm{H}, \mathrm{NH}$ ). MS (EI, $m / z(\%)$ ): 259 $\left(\mathrm{M}^{+}\right), 261\left(\mathrm{M}^{+}+2\right)$. Anal. calcd. for $\mathrm{C}_{9} \mathrm{H}_{10} \mathrm{~N}_{3} \mathrm{O}_{2} \mathrm{SCl}$ : C, 41.62; $\mathrm{H}$, 3.88; N, 16.18; S, 12.32. Found: C, 41.56; H, 3.85; N, 16.20; S, $12.31 \%$.

\subsubsection{Synthesis of 3,6-diacetyl-5-methylthiazolo[2,3-c]-1,2,4- triazole (5)}

A solution of the hydrazone $3(10 \mathrm{mmol})$ in pyridine $(20$ $\mathrm{mL}$ ) was heated under reflux for $4 \mathrm{~h}$, then left to cool, then dilute with ice water containing few drops of hydrochloric acid. The separated solid was collected by filtration, washed with water, dried and finally recrystallized from DMF to afford of compound 5 (Scheme 1). Yield: $46 \%$. M.p.: $287-289{ }^{\circ} \mathrm{C}$. FT-IR (KBr, $\left.v, \mathrm{~cm}^{-1}\right): 1698,1687$ (2C=0). ${ }^{1} \mathrm{H}$ NMR $\left(300 \mathrm{MHz}\right.$, DMSO-d ${ }_{6}$, $\delta, \mathrm{ppm}): 2.31\left(\mathrm{~s}, 3 \mathrm{H}, \mathrm{CH}_{3}\right), 2.62\left(\mathrm{~s}, 3 \mathrm{H}, \mathrm{CH}_{3}\right), 2.71\left(\mathrm{~s}, 3 \mathrm{H}, \mathrm{CH}_{3}\right)$. ${ }^{13} \mathrm{C}$ NMR (75 MHz, DMSO- $d_{6}, \delta$, ppm): 192.3, 190.9 (2CO), 167.3 (C-3), 159.8 (C-7a), 126.7 (C-5), 124.8 (C-6), 25.5, 23.5, 16.4 $\left(3 \mathrm{CH}_{3}\right)$. MS (EI, $\left.m / z(\%)\right): 223\left(\mathrm{M}^{+}\right)$. Anal. calcd. for $\mathrm{C}_{9} \mathrm{H}_{9} \mathrm{~N}_{3} \mathrm{O}_{2} \mathrm{~S}$ : C, 48.42; H, 4.06; N, 18.82; S, 14.36. Found: C, 48.38; H, 4.10; N, 18.86; S, $14.32 \%$.

\subsubsection{Synthesis of 1,1'-(5-methylthiazolo[2,3-c]-1,2,4- triazole-3,6-diyl)bis((2-bromo)ethanone) (6)}

A solution of the 3,6-diacetyl-5-methylthiazolo[2,3-c]-1,2,4triazole $5(20 \mathrm{mmol})$ in $\mathrm{AcOH}(50 \mathrm{~mL})$ was heated at $90-100{ }^{\circ} \mathrm{C}$ with stirring. To the hot solution, bromine $(40 \mathrm{mmol})$ in $\mathrm{AcOH}$ $(20 \mathrm{~mL})$ was added dropwise over a period of $30 \mathrm{~min}$ with stirring, maintaining the temperature at $90-100{ }^{\circ} \mathrm{C}$. After complete addition, the mixture was stirred vigorously at room temperature for further $1 \mathrm{~h}$, until evolution of hydrogen bromide ceased. The reaction mixture was allowed to cool and the precipitated solid was filtered off, washed with water, dried and finally recrystallized from ethanol to afford of compound 6 (Scheme 2). Yield: $52 \%$. M.p.: $213-215^{\circ} \mathrm{C}$. FT-IR $\left(\mathrm{KBr}, v, \mathrm{~cm}^{-1}\right)$ : 1684, 1692 (2C=0). ${ }^{1} \mathrm{H}$ NMR (300 MHz, DMSO- $\left.d_{6}, \delta, \mathrm{ppm}\right): 2.32$ $\left(\mathrm{s}, 3 \mathrm{H}, \mathrm{CH}_{3}\right), 4.29\left(\mathrm{~s}, 2 \mathrm{H}, \mathrm{CH}_{2}\right), 4.38\left(\mathrm{~s}, 2 \mathrm{H}, \mathrm{CH}_{2}\right) . \mathrm{MS}(\mathrm{EI}, \mathrm{m} / z$ (\%)): $381\left(\mathrm{M}^{+}\right)$. Anal. calcd. for $\mathrm{C}_{9} \mathrm{H}_{7} \mathrm{~N}_{3} \mathrm{O}_{2} \mathrm{SBr}_{2}$ : C, 28.37; $\mathrm{H}, 1.85$; N, 11.03; S, 8.42. Found: C, 28.41; H, 1.89; N, 11.10; S, 8.38\%.

\subsubsection{Synthesis of 3,3'-(5-methylthiazolo[2,3-c]-1,2,4- triazole-3,6-diyl)bis(3-oxopropanenitrile) (7)}

To a solution of compound 6 (15 mmol) in absolute ethanol ( $50 \mathrm{~mL}$ ) was added a solution of KCN (30 mmol in $15 \mathrm{~mL} \mathrm{H}_{2} \mathrm{O}$ ) with stirring. The reaction mixture was heated on a boiling water bath. The reaction mixture was left at room temperature for $24 \mathrm{~h}$, with stirring, then diluted with $\mathrm{H}_{2} \mathrm{O}$. The solid that precipitated was filtered off, washed with water, dried and finally recrystallized from EtOH to afford of compound 7 (Scheme 2). Yield: $48 \%$. M.p.: $228-230{ }^{\circ} \mathrm{C}$. FT-IR $\left(\mathrm{KBr}, \mathrm{v}, \mathrm{cm}^{-1}\right)$ : 1685, $1695(2 \mathrm{C}=0), 2213,2223(2 \mathrm{CN}) .{ }^{1} \mathrm{H}$ NMR $(300 \mathrm{MHz}$, DMSO- $\left.d_{6}, \delta, \mathrm{ppm}\right): 2.32\left(\mathrm{~s}, 3 \mathrm{H}, \mathrm{CH}_{3}\right), 4.50\left(\mathrm{~s}, 2 \mathrm{H}, \mathrm{CH}_{2}\right), 4.59(\mathrm{~s}$, $\left.2 \mathrm{H}, \mathrm{CH}_{2}\right) .{ }^{13} \mathrm{C}$ NMR $\left(75 \mathrm{MHz}\right.$, DMSO- $\left.d_{6}, \delta, \mathrm{ppm}\right): 196.1,197.3$ $(2 \mathrm{C}=0), 166.5$ (C-3), 158.2 (C-7a), 126.4 (C-5), 123.7 (C-6), $116.4(2 \mathrm{CN}), 26.1,23.5\left(2 \mathrm{CH}_{2}\right), 16.8\left(\mathrm{CH}_{3}\right)$. MS (EI, $\left.m / z(\%)\right)$ : $273\left(\mathrm{M}^{+}\right)$. Anal. calcd. for $\mathrm{C}_{11} \mathrm{H}_{7} \mathrm{~N}_{5} \mathrm{O}_{2} \mathrm{~S}: \mathrm{C}, 48.35 ; \mathrm{H}, 2.58 ; \mathrm{N}$, 25.63; S, 11.73. Found: C, 48.42; H, 2.60; N, 25.61; S, 11.68\%.

\subsubsection{Synthesis of 3,3'-(5-methylthiazolo[2,3-c]-1,2,4- triazole-3,6-diyl)bis(2-(bis(methylthio)methylene)-3-oxo propanenitrile) (8)}

To a stirred solution of sodium hydride $(40 \mathrm{mmol})$ in DMSO $(20 \mathrm{~mL})$, compound $7(10 \mathrm{mmol})$ was added. The resulting mixture was stirred for $1 \mathrm{~h}$, and then $\mathrm{CS}_{2}(20 \mathrm{mmol})$ was added and the stirring was continued for additional $6 \mathrm{~h}$, and then $\mathrm{CH}_{3} \mathrm{I}$ (20 mmol) was added dropwise. Stirring continued for additional $6 \mathrm{~h}$. The resulting reaction mixture was then poured onto crushed ice and the solid product was filtered off, washed with water, dried and finally recrystallized from $\mathrm{EtOH}$ to afford of compound 8 (Scheme 3). Yield: $62 \%$. M.p.: 206-208 ${ }^{\circ} \mathrm{C}$. FT-IR (KBr, v, cm-1): 1683, 1692 (2C=0); 2216, 2220 (2CN). ${ }^{1} \mathrm{H}$ NMR (300 MHz, DMSO- $\left.d_{6}, \delta, \mathrm{ppm}\right): 2.35\left(\mathrm{~s}, 3 \mathrm{H}, \mathrm{CH}_{3}\right), 2.63(\mathrm{~s}, 6 \mathrm{H}$, $\left.\mathrm{SCH}_{3}\right) 2.79$ (s, 6H, $\left.\mathrm{SCH}_{3}\right) .{ }^{13} \mathrm{C}$ NMR $\left(75 \mathrm{MHz}\right.$, DMSO- $\left.d_{6}, \delta, \mathrm{ppm}\right)$ : 187.9, 186.7 (2C=0), 187.9, 186.1 (=CSMe), 165.3 (C-3), 157.2 (C-7a), 127.2 (C-5), 137.6 (C-6), 115.9 (CN), 107.2, 92.4 (=CCN), $17.5\left(\mathrm{SCH}_{3}\right), 17.1\left(\mathrm{CH}_{3}\right)$. MS (EI, $\left.m / z(\%)\right): 483\left(\mathrm{M}^{+}+2\right)$. Anal. calcd. for $\mathrm{C}_{17} \mathrm{H}_{15} \mathrm{~N}_{5} \mathrm{O}_{2} \mathrm{~S}$ : C, 42.39; H, 3.14; N, 14.54; S, 33.29. Found: C, 42.34; H, 3.18; N, 14.58; S, 33.36\%.

\subsubsection{Synthesis of (5-methylthiazolo[2,3-c][1,2,4]triazole- 3,6-diyl)bis((3-amino-5-(methylthio)-1H-pyrazol-4- yl)methanone) (10)}

To a solution of compound $8(10 \mathrm{mmol})$ in EtOH $(25 \mathrm{~mL})$, hydrazine hydrate $(80 \%, 20 \mathrm{mmol})$ was added and the reaction mixture was refluxed for $4 \mathrm{~h}$, and then left to cool. The solid product so formed was filtered off, washed with EtOH, dried and finally recrystallized from DMF: $\mathrm{H}_{2} \mathrm{O}(1: 1, v: v)$ to afford of compound 10 (Scheme 3). Yield: 52\%. M.p.: 312-314 ${ }^{\circ} \mathrm{C}$. 
<smiles>CC(=O)c1sc2nnc(C(C)=O)n2c1C(=O)OCC(=O)c1sc2nnc(C(=O)OCc3ccccc3)n2c1C</smiles>

Scheme 2<smiles></smiles><smiles>CSc1[nH]nc(N)c1C(=O)c1nnc2sc(C(=O)c3c(N)n[nH]c3C(C)(C)C)c(C)n12</smiles>

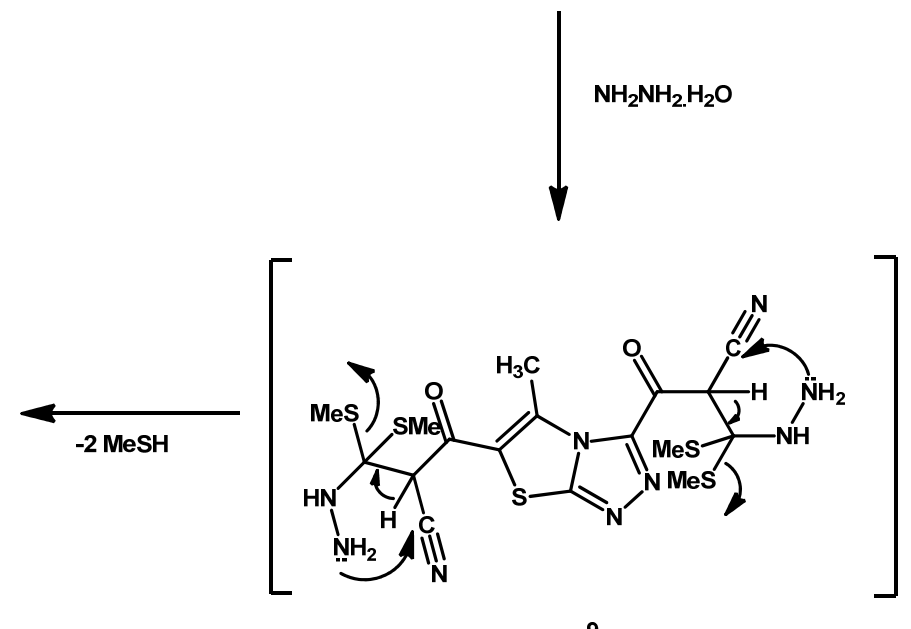

Scheme 3

FT-IR (KBr, v, cm-1): 3421, 3356, 3291, $3228\left(\mathrm{NH}\right.$ and $\left.\mathrm{NH}_{2}\right)$, 1685, $1692(2 \mathrm{C}=0) .{ }^{1} \mathrm{H}$ NMR (300 MHz, DMSO- $\left.d_{6}, \delta, \mathrm{ppm}\right): 2.35$ (s, 3H, $\left.\mathrm{CH}_{3}\right), 2.61\left(\mathrm{~s}, 3 \mathrm{H}, \mathrm{SCH}_{3}\right), 2.72$ (s, 3H, $\left.\mathrm{SCH}_{3}\right) 5.93$ (brs, 4H, $\mathrm{NH}_{2}, \mathrm{D}_{2} \mathrm{O}$-exchangeable), 8.36 (brs, $2 \mathrm{H}, \mathrm{NH}, \mathrm{D}_{2} \mathrm{O}$-exchangeable). MS (EI, $m / z(\%)): 451\left(\mathrm{M}^{+}+2\right)$. Anal. calcd. for $\mathrm{C}_{15} \mathrm{H}_{15} \mathrm{~N}_{9} \mathrm{O}_{2} \mathrm{~S}_{3}$ : C, 40.08; H, 3.36; N, 28.04; S, 21.40. Found: C, 40.12; H, 3.31; N, 27.98; S, $21.46 \%$.

\subsubsection{Synthesis of 3,3'-(5-methylthiazolo[2,3-c]-1,2,4- triazole-3,6-diyl)bis(2-(4-oxo-1,3-dithiolan-2-ylidene)-3- oxopropanenitrile) (11)}

To a stirred solution of $\mathrm{KOH}(10 \mathrm{mmol})$ in DMF $(30 \mathrm{~mL})$, compound 7 ( $5 \mathrm{mmol}$ ) was added, after stirring for $1 \mathrm{~h}, \mathrm{CS}_{2}(10$ $\mathrm{mmol}$ ) was added to the resulting mixture. Stirring was continued for $12 \mathrm{~h}$, and then chloroacetyl chloride (10 mmol) was added dropwise. Stirring was continued for additional $8 \mathrm{~h}$, then the reaction mixture was poured onto ice water. The solid product that formed was filtered off, dried and finally recrystallized from EtOH afford of compound 11 (Scheme 4). Yield: $64 \%$. M.p.: $295-297^{\circ} \mathrm{C}$. FT-IR (KBr, v, $\left.\mathrm{cm}^{-1}\right)$ : 2196, 2202 (2CN), 1716, 1698, 1668 (C=0). ${ }^{1} \mathrm{H}$ NMR (300 MHz, DMSO- $d_{6}, \delta$, ppm): 2.35 (s, 3H, $\mathrm{CH}_{3}$ ), 3.63 (brs, $4 \mathrm{H}, \mathrm{CH}_{2}$ ). MS (EI, $m / z(\%)$ ):
$505\left(\mathrm{M}^{+}\right)$. Anal. calcd. for $\mathrm{C}_{17} \mathrm{H}_{7} \mathrm{~N}_{5} \mathrm{O}_{4} \mathrm{~S}_{5}$ : C, 40.38; $\mathrm{H}, 1.40$; , 13.85; S, 31.71. Found: C, 40.45; H, 1.48; N, 13.81; S, 31.76\%.

2.2.8. Synthesis of 3,3'-(5-methylthiazolo[2,3-c]-1,2,4triazole-3,6-diyl)bis(2-(4-oxo-(5-phenylhydrazono)-1,3dithiolan-2-ylidene)-3-oxopropanenitrile) (12)

To a solution of $\mathbf{1 1}(5 \mathrm{mmol})$ in pyridine $(20 \mathrm{~mL})$, an icecooled solution of the aniline diazonium salt $(15 \mathrm{mmol})$ was added dropwise with stirring for $30 \mathrm{~min}$, after which water was added and the precipitate product was filtered off, washed with water several times, dried and finally recrystallized from DMF: $\mathrm{H}_{2} \mathrm{O}(1: 1, v: v)$ to give of compound $\mathbf{1 2}$ (Scheme 4). Yield: 53\%. M.p.: $264-266^{\circ} \mathrm{C}$. FT-IR (KBr, v, $\left.\mathrm{cm}^{-1}\right): 3317,3237(\mathrm{NH}), 2221$, 2235 (CN), 1698, 1684, 1676 (C=0). ${ }^{1} \mathrm{H}$ NMR (300 MHz, DMSO$\left.d_{6}, \delta, \mathrm{ppm}\right): 2.34\left(\mathrm{~s}, 3 \mathrm{H}, \mathrm{CH}_{3}\right), 7.23-7.86(\mathrm{~m}, 10 \mathrm{H}, \mathrm{Ar}), 11.91$ (brs, $2 \mathrm{H}, \mathrm{NH}, \mathrm{D}_{2} \mathrm{O}$-exchangeable). Anal. calcd. for $\mathrm{C}_{29} \mathrm{H}_{15} \mathrm{~N}_{9} \mathrm{O}_{4} \mathrm{~S}_{5}$ : C, 48.80; H, 2.12; N, 17.66; S, 22.46. Found: C, 48.86; H, 2.15; N, $17.61 ; \mathrm{S}, 22.49 \%$.

2.2.9. Synthesis of 4,4'-(5-methylthiazolo[2,3-c]-1,2,4triazole-3,6-diyl)bis(5-benzoyl-2-(phenyl-amino)thiophene3-carbonitrile) (15) 


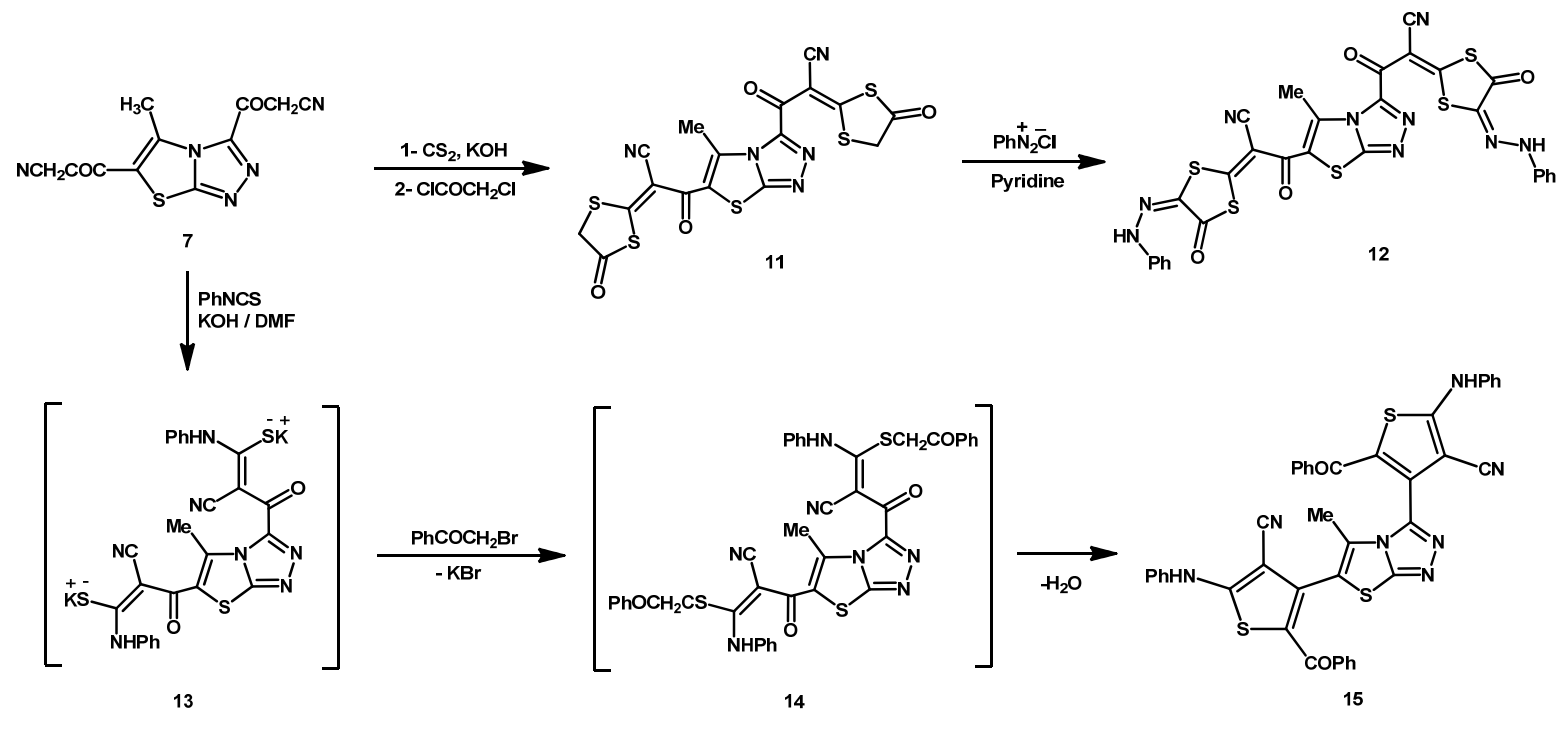

Scheme 4

To a stirred solution of $\mathrm{KOH}(10 \mathrm{mmol})$ in DMF (30 mL), compound 7 ( $10 \mathrm{mmol}$ ) was added, after stirring for $1 \mathrm{~h}$, phenyl isothiocyanate $(20 \mathrm{mmol})$ was added to the resulting mixture. The reaction was stirred for additional $6 \mathrm{~h}$, during which the 2-bromo-1-phenylethanone went into solution and a yellow product precipitated. The solid product was filtered off, washed with water, dried and finally recrystallized from DMF: EtOH $(1: 2, v: v)$ afforded of compound 15 (Scheme 4). Yield: 59\%. M.p.: > $330{ }^{\circ}$ C. FT-IR (KBr, v, cm-1): 3298, 3218 (NH), 2218, 2224 (CN), 1665, 1669 (C=0). ${ }^{1} \mathrm{H}$ NMR (300 MHz, DMSO- $d_{6}, \delta$, ppm): 2.35 (s, $\left.3 \mathrm{H}, \mathrm{CH}_{3}\right), 7.21-7.83(\mathrm{~m}, 20 \mathrm{H}, \mathrm{ArH}), 10.93$ (brs, $2 \mathrm{H}$, $\mathrm{NH}, \mathrm{D}_{2} \mathrm{O}$-exchangeable). Anal. calcd. for $\mathrm{C}_{41} \mathrm{H}_{25} \mathrm{~N}_{7} \mathrm{O}_{2} \mathrm{~S}_{3}$ : C, 66.20; H, 3.39; N, 13.18; S, 12.93. Found: C, 66.17; H, 3.45; N, 13.11; S, $12.88 \%$.

\subsubsection{Synthesis of 2,2'-(5-methylthiazolo[2,3-c][1,2,4] triazole-3,6-dicarbonyl)bis(3-(methylthio)-3-(phenyl amino)acrylonitrile) (16)}

To a stirred solution of $\mathrm{KOH}(20 \mathrm{mmol})$ in DMF $(30 \mathrm{~mL})$ was added compound 7 (10 mmol). After stirring for $1 \mathrm{~h}$, phenyl isothiocyanate $(20 \mathrm{mmol})$ was added to the resulting mixture. Stirring continued for additional $6 \mathrm{~h}$ and then $\mathrm{CH}_{3} \mathrm{I}(20$ mmol) was added, stirring continued for additional $5 \mathrm{~h}$. Then, the reaction mixture was poured onto ice water. The solid product that formed was filtered off, washed with ethanol, dried and finally recrystallized from DMF: EtOH $(1: 2, v: v)$ to afford of compound 16 (Scheme 5). Yield: 63\%. M.p.: 312-314 ${ }^{\circ} \mathrm{C}$. FT-IR (KBr, v, cm${ }^{-1}$ ): 3392, $3268(\mathrm{NH}), 2223,2198(\mathrm{CN})$, 1698, $1694(\mathrm{C}=0)$. ${ }^{1} \mathrm{H}$ NMR (300 MHz, DMSO-d $\left.6, \delta, \mathrm{ppm}\right): 2.34$ $\left(\mathrm{s}, 3 \mathrm{H}, \mathrm{CH}_{3}\right), 2.83\left(\mathrm{~s}, 3 \mathrm{H}, \mathrm{SCH}_{3}\right), 2.89\left(\mathrm{~s}, 3 \mathrm{H}, \mathrm{SCH}_{3}\right), 7.23-7.96(\mathrm{~m}$, $10 \mathrm{H}, \mathrm{ArH}), 9.87$ (brs, $2 \mathrm{H}, \mathrm{NH}, \mathrm{D}_{2} \mathrm{O}$-exchangeable). MS (EI, $\mathrm{m} / \mathrm{z}$ (\%)): $572\left(\mathrm{M}^{+}+1\right)$. Anal. calcd. for $\mathrm{C}_{27} \mathrm{H}_{21} \mathrm{~N}_{7} \mathrm{O}_{2} \mathrm{~S}_{3}$ : C, $56.72 ; \mathrm{H}$, 3.70; N, 17.15; S, 16.83. Found: C, 56.66; H, 3.74; N, 17.09; S, $16.80 \%$.

\subsubsection{Synthesis of (5-methylthiazolo[2,3-c]-1,2,4-triazole- 3,6-diyl)bis((3-amino-5-(phenylamino)-1H-pyrazol-4-yl) methanone) (17)}

A mixture of 16 (10 mmol) and hydrazine hydrate $80 \%$, (25 $\mathrm{mmol}$ ) was heated on boiling water bath for $4 \mathrm{~h}$., then left to cool. The reaction mixture was triturated with ethanol and the resulting solid was filtered off, washed with EtOH, dried and finally recrystallized from DMF: EtOH $(1: 2, v: v)$ to afford of compound 17 (Scheme 5). Yield: $62 \%$. M.p.: $262-264{ }^{\circ} \mathrm{C}$. FT-IR $\left(\mathrm{KBr}, v, \mathrm{~cm}^{-1}\right): 3473,3376\left(\mathrm{NH}_{2}\right), 3285,3258,3225(\mathrm{NH}), 1686$, $1693(\mathrm{C}=0) .{ }^{1} \mathrm{H}$ NMR $\left(300 \mathrm{MHz}, \mathrm{DMSO}-d_{6}, \delta, \mathrm{ppm}\right): 2.35$ (s, 3H, $\left.\mathrm{CH}_{3}\right)$, 7.28-7.79 (m, 10H, Ar), 6.12 (brs, $4 \mathrm{H}, \mathrm{NH}_{2}, \mathrm{D}_{2} \mathrm{O}-$ exchangeable); 8.74 (brs, $2 \mathrm{H}, \mathrm{NH}, \mathrm{D}_{2} \mathrm{O}$-exchangeable), 9.25 (brs, $2 \mathrm{H}, \mathrm{NH}, \mathrm{D}_{2} \mathrm{O}$-exchangeable). ${ }^{13} \mathrm{C}$ NMR $\left(75 \mathrm{MHz}\right.$, DMSO- $d_{6}, \delta$, ppm): 187.8, 185.6 (2C0), 166.3 (C-3), 156.9 (C-7a), 156.1 (2C5 pyrazole), 153.3 (2C-3 pyrazole), 144.2 (2C-ArNH), 129.9116.9 (Ar-C), 129.7 (C-5), 123.7 (C-6), 99.2 (2C-4 pyrazole), $17.1\left(\mathrm{CH}_{3}\right)$. MS (EI, $\left.m / z(\%)\right)$ : $539\left(\mathrm{M}^{+}\right)$. Anal. calcd. for $\mathrm{C}_{25} \mathrm{H}_{21} \mathrm{~N}_{11} \mathrm{O}_{2} \mathrm{~S}: \mathrm{C}, 55.65 ; \mathrm{H}, 3.92 ; \mathrm{N}, 28.55 ; \mathrm{S}, 5.94$. Found: $\mathrm{C}$, 55.61; H, 3.87; N, 28.59; S, 5.99\%.

\subsubsection{Synthesis of (5-methylthiazolo[2,3-c]-1,2,4-triazole- 3,6-diyl)bis((3-amino-5-(phenylamino)-isoxazol-4-yl) methanone) (18)}

A solution of $15(10 \mathrm{mmol})$ in ethanol $(30 \mathrm{~mL})$ was treated with hydroxylamine hydrochloride $(20 \mathrm{mmol})$ and sodium carbonate. The reaction mixture was heated under reflux $6 \mathrm{~h}$, then left to cool. The reaction solid product was collected by filtration, washed with water several times, dried and finally recrystallized from DMF: $\mathrm{H}_{2} \mathrm{O}(1: 1, v: v)$ to afford of compound 18 (Scheme 5). Yield: 59\%. M.p.: 308-309 ${ }^{\circ} \mathrm{C}$. FT-IR (KBr, v, $\left.\mathrm{cm}^{-1}\right)$ : 3445, $3351\left(\mathrm{NH}_{2}\right), 3331,3241(\mathrm{NH}), 1689,1682(\mathrm{C}=0)$. ${ }_{1}^{1} \mathrm{H}$ NMR $\left(300 \mathrm{MHz}, \mathrm{DMSO}-d_{6}, \delta, \mathrm{ppm}\right): 2.35\left(\mathrm{~s}, 3 \mathrm{H}, \mathrm{CH}_{3}\right), 7.25-$ $7.76(\mathrm{~m}, 10 \mathrm{H}, \mathrm{Ar}), 5.71$ (brs, 4H, NH $2, \mathrm{D}_{2} \mathrm{O}$-exchangeable); 9.29 (brs, $2 \mathrm{H}, \mathrm{NH}, \mathrm{D}_{2} \mathrm{O}$-exchangeable). MS (EI, $\mathrm{m} / z(\%)$ ): $541\left(\mathrm{M}^{+}\right)$. Anal. calcd. for $\mathrm{C}_{25} \mathrm{H}_{19} \mathrm{~N}_{9} \mathrm{O}_{4} \mathrm{~S}$ : C, 55.45; H, 3.54; N, 23.28; S, 5.92. Found: C, 55.40; H, 3.57; N, 23.22; S, 5.87\%.

\subsubsection{Synthesis of (5-methylthiazolo[2,3-c]-1,2,4-triazole 3,6-diyl)bis(1-(4-amino-1,2-dihydro-6-(phenylamino)-2- thioxopyrimidin-5-yl)methanone) (19)}

A solution of compound $15(10 \mathrm{mmol})$ in $\mathrm{EtOH}(30 \mathrm{~mL})$ containing $\mathrm{Et}_{3} \mathrm{~N}(1 \mathrm{~mL})$ was treated with solution of thiourea $(20 \mathrm{mmol})$ in ethanol $(15 \mathrm{~mL})$. The reaction mixture was heated under reflux $16 \mathrm{~h}$, then the reaction was poured onto ice water. The solid product that for was filtered off, dried and finally recrystallized from DMF to afford of compound 19 (Scheme 5). Yield: $61 \%$. M.p.: $>332{ }^{\circ} \mathrm{C}$. FT-IR $\left(\mathrm{KBr}, v, \mathrm{~cm}^{-1}\right)$ : 3336, $3320\left(\mathrm{NH}_{2}\right), 3261,3158,3117(\mathrm{NH}), 1678(\mathrm{C}=0)$. 

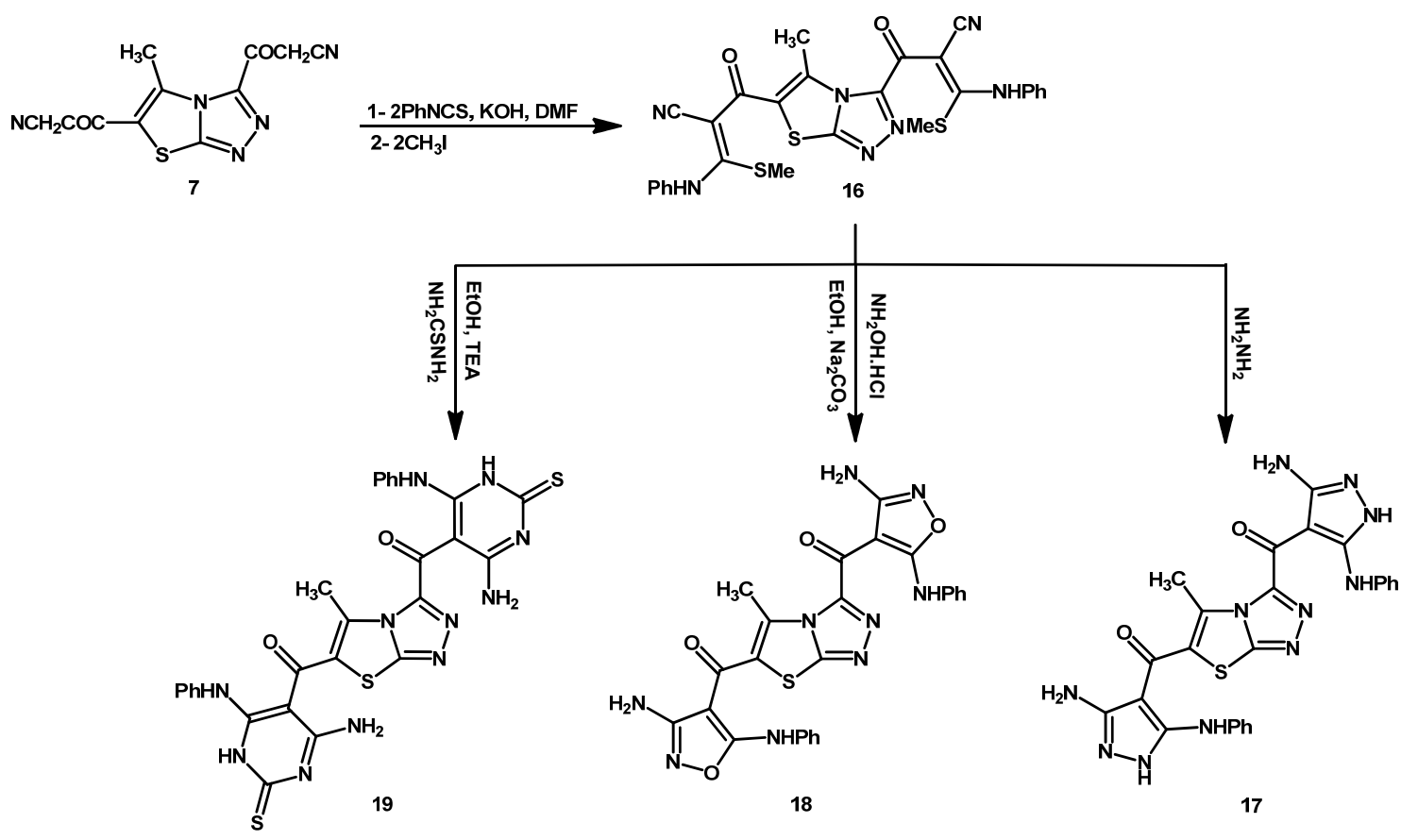

Scheme 5

${ }_{1}^{1} \mathrm{H}$ NMR (300 MHz, DMSO- $\left.d_{6}, \delta, \mathrm{ppm}\right): 2.34\left(\mathrm{~s}, 3 \mathrm{H}, \mathrm{CH}_{3}\right)$, 7.28-7.75 (m, 10H, Ar), 5.37 (brs, $4 \mathrm{H}, \mathrm{NH}_{2}, \mathrm{D}_{2} \mathrm{O}$-exchangeable); 8.89 (brs, $2 \mathrm{H}, \mathrm{NH}, \mathrm{D}_{2} \mathrm{O}$-exchangeable), 9.74 (brs, $2 \mathrm{H}, \mathrm{NH}, \mathrm{D}_{2} \mathrm{O}$ exchangeable). MS (EI, $m / z(\%)): 627\left(\mathrm{M}^{+}\right)$. Anal. calcd. for $\mathrm{C}_{27} \mathrm{H}_{21} \mathrm{~N}_{11} \mathrm{O}_{2} \mathrm{~S}_{3}$ : C, 51.66; H, 3.37; N, 24.54; S, 15.32. Found: C, 51.70; H, 3.34; N, 24.58; S, 15.28\%.

\section{Results and discussion}

It has been found that a buffered solution of 5-acetyl-2amino-4-methylthiazole diazonium sulfate (1) couple smoothly and in moderate yield with 3-chloropentane-2,4-dione (2) followed by Japp-Klingemann rearrangement to afford the corresponding hydrazine, (3) $[37,38]$. The structure of the latter product was established on the basis of its elemental analyses and spectral data. Its ${ }^{1} \mathrm{H}$ NMR spectrum revealed $\mathrm{D}_{2} \mathrm{O}-$ exchangeable broad singlet signal at $\delta 9.88 \mathrm{ppm}$ assignable to hydrazone $\mathrm{NH}$ proton. The absence of any other $\mathrm{CH}$ signal in the ${ }^{1} \mathrm{H}$ NMR spectrum of compound 3 excludes the presence of the azo tautomer (4).

Compound 3 undergoes a facile intramolecular cyclisation to the corresponding 3,6-diacetyl-5-methylthiazolo[2,3-c]1,2,4-triazole (5) upon refluxing in pyridine via loss of hydrogen chloride [37,38] (Scheme 1). The product 5 gave analytical and spectral data consist with its assigned structure. Its IR spectra showed the disappearance of $\mathrm{NH}$ absorption and revealed absorption bands at 1687 and $1698 \mathrm{~cm}^{-1}$ assignable to two carbonyl groups. Its ${ }^{1} \mathrm{H}$ NMR spectrum revealed two singlet signals at $\delta 2.62$ and $2.71 \mathrm{ppm}$ assignable to two acetyl protons, respectively.

Bormination of compound $\mathbf{5}$ afforded 1,1'-(5-methyl thiazolo[2,3-c]-1,2,4-triazole-3,6-diyl)bis((2-bromo)ethanone) (6). The structure of compound $\mathbf{6}$ was established on the basis of elemental and spectral data. Its IR showed absorption bands at 1684 and $1692 \mathrm{~cm}^{-1}$ for two carbonyl groups. The ${ }^{1} \mathrm{H}$ NMR spectrum revealed absorption bands at $\delta 4.29$ and $4.38 \mathrm{ppm}$ assignable to methylene protons.

Treatment of compound 6 with ethanolic potassium cyanide solution furnished 3,3'-(5-methylthiazolo[2,3-c]-1,2,4- triazole-3,6-diyl)bis(3-oxopropanenitrile) (7). Its IR spectrum revealed absorption bands at 2213 and $2223 \mathrm{~cm}^{-1}$ for two cyano functions and absorption bands at 1689 and $1696 \mathrm{~cm}^{-1}$ for two carbonyl groups. Its ${ }^{1} \mathrm{H}$ NMR spectrum revealed two singlet signals at $\delta 4.50$ and $4.59 \mathrm{ppm}$ assignable to methylene protons (Scheme 2).

The ketene $S, S$-dithioacetals (8) was prepared by the reaction of 3,3'-(5-methylthiazolo[2,3-c]-1,2,4-triazole-3,6-diyl) bis(3-oxopropanenitrile) 7 with sodium hydride and carbon disulfide followed by alkylation with methyl iodide afforded 3,3'-(5-methylthiazolo[2,3-c]-1,2,4-triazole-3,6-diyl)bis(2-(bis (methylthio)methylene)-3-oxopropanenitrile), 8.

The structure of compound $\mathbf{8}$ was elucidated on the basis of its elemental analysis and spectral data. The IR spectrum showed the appearance of absorption bands at 2216, $2220 \mathrm{~cm}^{-1}$ and 1692, $1683 \mathrm{~cm}^{-1}$ for cyano and carbonyl functions, respectively. Its ${ }^{1} \mathrm{H}$ NMR spectrum revealed two singlet signals at $\delta 2.63$ and $2.79 \mathrm{ppm}$ assignable to methyl protons while the singlet signal for the methylene protons of compound $\mathbf{7}$ was disappeared.

Reaction of compound 8 with hydrazine hydrate gave (5methyl-thiazolo[2,3-c]-1,2,4-triazole-3,6-diyl) bis(3-amino5-(methylthio)-1H-pyrazol-4-yl)methanone, (10). The structure of compound $\mathbf{1 0}$ was elucidated on the basis of the elemental analysis and spectral data. The IR spectrum displayed stretching absorption bands at 3421 and $3356 \mathrm{~cm}^{-1}$ due to the two formed $\mathrm{NH}_{2}$ and two $\mathrm{NH}$ functions at 3291 and $3228 \mathrm{~cm}^{-1}$, while carbonyl absorption band appeared at 1685 and $1692 \mathrm{~cm}^{-1}$. Its ${ }^{1} \mathrm{H}$ NMR spectrum revealed two signals at $\delta$ 2.61 and $2.72 \mathrm{ppm}$ assigned for $\mathrm{SCH}_{3}$ protons, in addition to $\mathrm{D}_{2} \mathrm{O}$-exchangeable signals at $\delta 5.93$ and $8.36 \mathrm{ppm}$ due to $\mathrm{NH}_{2}$ and $\mathrm{NH}$ protons, respectively (Scheme 3 ).

Reaction of compound $\mathbf{7}$ with carbon disulfide in DMF containing potassium hydroxide followed by addition of chloroacetyl chloride afforded 3,3'-(5-methylthiazolo[2,3-c]1,2,4-triazole-3,6-diyl) bis(2-(4-oxo-1,3-dithiolan-2-ylidene)-3oxopropanenitrile, (11). The IR spectrum of compound 11 displayed absorption bands for CN at 2196, $2202 \mathrm{~cm}^{-1}$ and at 1716, 1698, $1668 \mathrm{~cm}^{-1}$ for carbonyl functions. Its ${ }^{1} \mathrm{H}$ NMR 
spectrum displayed singlet signal at $\delta 3.63 \mathrm{ppm}$ assignable for the newly methylene protons.

The active methylene group in 3,3'-(5-methylthiazolo[2,3c]-1,2,4-triazole-3,6-diyl)bis(2-(4-oxo-1,3-dithiolan-2-ylidene)3-oxopropanenitrile $\mathbf{1 1}$ coupled smoothly with benzene diazonium salt yielded 3,3'-(5-methylthiazolo[2,3-c]-1,2,4triazole-3,6-diyl) bis(2-(4-oxo-(5-phenylhydrazono)-1,3-dithio lan-2-ylidene)-3-oxopropanenitrile, (12). The structure of compound 12 was elucidated on the basis of spectral data. The IR spectrum showed absorption bands at $3317,3237 \mathrm{~cm}^{-1}$ due to $\mathrm{NH}$, at $2221,2235 \mathrm{~cm}^{-1}$ due to $\mathrm{CN}$ and at $1698,1684,1668$ $\mathrm{cm}^{-1}$ due to carbonyl functions. Its ${ }^{1} \mathrm{H}$ NMR spectrum showed the absence of a singlet signal assignable for methylene protons, while showed a new signal at $\delta 11.91 \mathrm{ppm}$ for hydrazo protons.

The nucleophilic addition of 3,3'-(5-methylthiazolo[2,3-c]1,2,4-triazole-3,6-diyl)bis(3-oxopropanenitrile) $\mathbf{7}$ to phenyl isothiocayante in DMF in the presence of $\mathrm{KOH}$ afforded the corresponding potassium salt, (13). Heterocyclization of the intermediate $\mathbf{1 3}$ with an equimolar amount of the phenacyl bromide furnished one isolable product. The reaction product was identified as 4,4'-(5-methylthiazolo[2,3-c]-1,2,4-triazole3,6-diyl)bis(5-benzoyl-2-(phenylamino)thiophene-3-carbonitri le), (15). Its IR displayed absorption bands at 3298, 3218 due to $\mathrm{NH}$ function and absorption bands at $2218,2224 \mathrm{~cm}^{-1}$ due to CN. Its ${ }^{1} \mathrm{H}$ NMR spectrum showed singlet signal at $\delta 10.93 \mathrm{ppm}$ $\mathrm{D}_{2} \mathrm{O}$-exchangeable peak due to two $\mathrm{NH}$ protons, in addition to an aromatic multiplet in the region $\delta 7.21-7.83 \mathrm{ppm}$. The aforementioned results indicate that the reaction of the intermediate 13 with phenacyl bromide proceed via loss of two water molecules from the non-isolable intermediate $\mathbf{1 4}$ (Scheme 4).

Polarized cyanoketene $N, S$-acetal are versatile starting materials for the synthesis of a wide variety of fused heterocycles [39]. So, further reaction of compound $\mathbf{7}$ with phenyl isothiocyanate in DMF containing $\mathrm{KOH}$ followed by addition of methyl iodide to afford 2,2'-(5-methylthiazolo[2,3c] [1,2,4] triazole-3,6-dicarbonyl)bis(3-(methylthio)-3-(pheny lamino)acrylonitrile), (16).

The assignment of the structure 16 was based on elemental analysis and spectral data. Its IR spectrum showed absorption bands at 3392 and $3268 \mathrm{~cm}^{-1}$ for NH functions, absorption band at $2198,2223 \mathrm{~cm}^{-1}$ for nitrile groups and two strong absorption bands at 1694 and $1698 \mathrm{~cm}^{-1}$ for two carbonyl groups. Its ${ }^{1} \mathrm{H}$ NMR spectrum displayed no signal for methylene protons, while a strong singlet signal at $\delta 2.83$ and $2.89 \mathrm{ppm}$ for two methylthio protons and a broad signal at $\delta 9.87 \mathrm{ppm}$ were appeared for $\mathrm{NH}$ protons.

Compound $\mathbf{1 6}$ was utilized as a starting material for the preparation of wide variety of fused heterocyclic compounds by reaction with bifunctional nucleophilic reagents. Refluxing of 16 with hydrazine hydrate afforded (5-methylthiazolo[2,3c]-1,2,4-triazole-3,6-diyl) bis((3-amino-5-(phenylamino)$1 H$-pyrazol-4-yl)methanone), (17). The structure of compound 17 was elucidated on the basis of the elemental analysis and spectral data.

Refluxing of compound $\mathbf{1 6}$ with hydroxyl amine hydrochloride in ethanolic sodium carbonate afforded (5methylthiazolo[2,3-c]-1,2,4-triazole-3,6-diyl) bis((3-amino-5(phenyl-amino)isoxazole-4-yl)methanone), (18). The structure of compound 18 was elucidated on the basis of the elemental analysis and spectral data. The IR spectrum displayed stretching absorption bands at $3445,3351 \mathrm{~cm}^{-1}$ due to the formed amino groups and absorption bands for $\mathrm{NH}$ functions at $3331,3241 \mathrm{~cm}^{-1}$, while carbonyl absorption band appeared at $1682 \mathrm{~cm}^{-1}$

Treatment of compound $\mathbf{1 6}$ with thiourea in ethanol containing catalytic amount of triethylamine as a basic catalyst afforded the (5-methylthiazolo[2,3-c]-1,2,4-triazole-3,6-diyl) bis (1-(4-amino-1,2-dihydro-6-(phenylamino)-2-thioxopyrimidin- 5-yl)methanone), (19). The structure of compound 19 was elucidated on the basis of the elemental analysis and spectral data. Its ${ }^{1} \mathrm{H}$ NMR spectrum exhibited appearance of a broad signal at $\delta 5.37 \mathrm{ppm}$ assignable for two newly formed amino protons, a broad signal at $\delta 8.89 \mathrm{ppm}$ and $\delta 9.74 \mathrm{ppm}$ for $\mathrm{NH}$ and $\mathrm{NH}$ protons, respectively, in addition to an aromatic multiplet in the region $\delta$ 7.28-7.75 ppm (Scheme 5).

\section{Conclusion}

A series of novel thiazolo[2,3-c]-1,2,4-triazole were prepared with good to moderate yields could be considered as good candidates for future research to develop high potency anti-inflammatory agents.

\section{Acknowledgement}

Authors are thankful to Aswan Faculty of Science, Aswan University, Egypt for facilities.

\section{References}

[1]. Pattan, S. R.; Reddy, K. V. V.; Manvi, F. V.; Desai, B. G.; Bhat, A. R. Indian J. Chem. 2006, 45B, 1778-1781.

[2]. Pattan, S. R.; Shamrez, A. M.; Pattan, J. S.; Purohit, S. S.; Reddy, K. V. V.; Nataraj, B. R. Indian J. Chem. 2006, 45B, 1929-1932.

[3]. Narayana, B.; Raj, K. K. V.; Ashalatha, B. V.; Kumari, N. S. Indian J. Chem. 2006, 45B, 1704-1709.

[4]. Altintas, H.; Ates, O.; Kocabalkanli, A.; Birteksoz, S.; Otuk, G. Indian J Chem. 2005, 44B, 585-509.

[5]. Kane, J. M.; Baron, B. M.; Dudley, B. M.; Sorensen, S. M.; Staeger, M. A. Miller, F. P. J. Med. Chem. 1990, 33, 2772-2777.

[6]. Kucukguzel, I.; Kucukguzel, S. G.; Rollas, S.; Otuk-Sanis, G.; Ozdemir, O. Bayrak, I.; Altug, T.; Stables, J. P. II Farmaco 2004, 59, 893-901.

[7]. Modi, V. P.; Jani, D. H.; Patel, H. S. Orbital Elec. J. Chem. Campo Grand. 2011, 3, 68-79.

[8]. Rollas, S.; Kalyoncuoghu, N.; Sur-Altiner, D.; Yegenouglu, Y. Pharmazie 1993, 48, 308-309.

[9]. Chollet, J. F.; Bonnemain, J. L.; Miginiac, L.; Rohr, O. J. Pestic. Sci. 1990 29, 427-435.

[10]. Murabayashi, A.; Masuko, M.; Niikawa, M.; Shirane, N.; Futura, T. Hayashi, Y.; Makisumi, Y. J. Pestic. Sci. 1991, 16, 419-427.

[11]. Gilbert, B. E.; Knight, V. Antimicrob. Agents Chemother. 1986, 30, 201205.

[12]. Holla, B. S.; Veerendra, B.; Shivanada, M. K.; Poojary, B. Eur. J. Med. Chem. 2003, 38, 759-767.

[13]. Turan-Zitoumi, G.; Sivaci, M. F.; Kilic, S.; Erol, K. Eur. J. Med. Chem. 2001, 36, 685-689.

[14]. Bekircan, O.; Kucuk, M.; Kahveci, B.; Kolayli, S. Arch. Pharm. 2005, 338 , 365-372.

[15]. Wade, P. C.; Vogt, B. R.; Kissick, T. P.; Simpkins, L. M.; Palmer, D. M.; Millonig, R. C. J. Med. Chem. 1982, 25, 331-333.

[16]. Gruta, A. R.; Bhargava, K. P. Pharmazie 1978, 33, 430-434.

[17]. Modzelewska, B.; Kalabun, J. Pharmazie 1999, 54, 503-505.

[18]. Malbec, F.; Milcent, R.; Vicart, P.; Bure, A. M. J. Heterocycl. Chem. 1984, 21, 1769.

[19]. Milcent, R.; Vicart, P.; Bure, A. M. Eur. J. Med. Chem. 1983, 18, 215-217.

[20]. Gulerman, N.; Rollas, S.; Kiraz, M.; Ekinci, A. C.; Vidin, A. II Farmaco 1997, 52, 691-695.

[21]. Ikizler, A. A.; Johansson, C. B.; Bekircan, O.; Celik, C. Acta Polon. PharmDrug Res. 1999, 56, 283-288.

[22]. Shujuan, S.; Hongxiang, L.; Gao, Y.; Fan, P.; Ma, B.; Ge, W.; Wang, X. J. Pharm. Miomed. Anal. 2004, 34, 1117-1124.

[23]. Clemon, M.; Coleman, R. E.; Verma, S. Cancer Treat. Rev. 2004, 30, 325332.

[24]. Johnston, G. A. R. Curr. Top. Med. Chem. 2002, 2, 903-913.

[25]. Sauzem, P. D.; Machado, P.; Rubin, M.; Das, S. G.; Faber, H. B.; Souza, A H.; Mello, C. F.; Beck, P.; Burrow, R. A.; Bonacorso, H. G.; Zanatta, N.; Martins, M. A. Eur. J. Med. Chem. 2008, 43, 1237-1247.

[26]. Abu-Melha, S. Archiv der Pharmazie 2013, 346, 912-921.

[27]. Chakrabarti, J. K.; Horsman, L.; Hotten, T. M.; Pullar, I. A.; Tupper, D. E.; Wright, F. C. J. Med. Chem. 1980, 23, 878-884.

[28]. Ram, V. J.; Pandey, H. K.; Vlientick, A. J. J. Heterocycl. Chem. 1981, 18, 1277-1280.

[29]. Mabkhot, Y. N.; Kheder, N. A.; Al-Majid, A. M. Molecules 2010, 15 9418-9426.

[30]. Sayed, S. M.; Selim, M. A.; Raslan, M. A.; Khalil, M. A. Heteroatom Chem. 2000, 11, 362-369.

[31]. Raslan, M. A. J. Chin. Chem. Soc. 2000, 47, 961-965.

[32]. Raslan, M. A.; Khalil, M. A. Heteroatom Chem. 2003, 14, 114-120.

[33]. Raslan, M. A.; Sayed, S. M. J. Chin. Chem. Soc. 2003, 50, 909-916. 
[34]. Sayed, S. M.; Khalil, M. A.; Ahmed, M. A.; Raslan, M. A. Synth. Comm. 2002, 32, 481-495.

[35]. Sayed, S. M.; Raslan, M. A.; Khali, M. A.; Dawood, K. M. Heteroatom Chem. 1999, 10, 385-390.

[36]. Maradiya, H. R.; Patel, V. S. J. Braz. Chem. 2001, 12. 710-714.

[37]. Ibrahim, M. K. A.; Elghandour, A. H.; Abou-hadeed, K. Phosphorus, Sulfur Silicon Relat. Elem. 1991, 60, 119-123.

[38]. Potts, K. T.; Husain, S. J. Org. Chem. 1971, 36, 10-13.

[39]. Fadda, A. A.; Mukhtar, M. M.; Refat, H. M. American J. Org. Chem. 2012, 2, 32-42. 